\title{
An Example of Tourism Industry Integration
}

\author{
Cai-Zhen $\mathrm{HONG}^{*}$ \\ College of Applied Science and Technology, Quanzhou Normal University, P.R. China, 362000 \\ Hongcaizhen2@126.com \\ ${ }^{*}$ Corresponding author
}

Keywords: Tourism industry, Incense cultural, Integration.

\begin{abstract}
Chinese incense culture has a long history, and is known with tea culture and flower culture as the three major cultural phenomena. Development of Quanzhou Maritime Silk Road incense culture tourism is to adjust tourism industrial structure, develop cultural creative tourism and promote Maritime Silk Road culture. It is feasible due to the exquisite life demand of of the people, historical background of Quanzhou Maritime Silk Road and the spice trade, and Chinese incense capital -- Yongchun Pushi incense technology. The integration of Quanzhou Maritime Silk Road incense culture and six elements of tourism industry can broaden the tourism industry chain, and promote the transformation and upgrading of tourism industry.
\end{abstract}

\section{The Origin of Chinese Incense Culture}

The incense culture began in the ancient, germinated in the pre Qin period, started in the Qin and Han Dynasties, grew in Six Dynasties, completed in the Sui and Tang Dynasties, flourished in Song Dynasty, and wide spread in the Ming and Qing Dynasties. [1] Incense culture of Han nationality in China is a series of goods, technology, methods and habits, system and concept that gradually formed to reflect the Han nationality spirit and tradition by various spices production, processing, and use during the long course of history. Incense culture, tea culture, and flower culture is known as the three major cultural phenomena in China.

The history of burning incense by Chinese ancestors can be traced back to the late Neolithic age, about 6000 years ago. The reasons of burning incense by ancestors were to offer sacrifices to heaven, for mosquito repellent and exorcise of evil spirits. [2] Early ceremonial incense is mainly burning firewood and offerings (wine and grain offerings, etc.), such as Oracle bone inscription records of the Shang Dynasty "hand holding the burning wood" offering. Incense for life use also has a long history, living supplies Tao Xunlu emerged as early as 4000 to 5000 years ago. In the pre Qin period, the use of perfume bag, vanilla had been popular. At the time of the Warring States sophisticated smoked furnace Boshan furnace had been produced; in the Emperor Wudi of Han Dynasty period (about $120 \mathrm{BC}$ ), incense and incense burner had been popular in the north and south parts among the nobilities; in the early Eastern Han Dynasty, spice medicine was abundant, and was regarded as enjoyment of life, a method of removing dirty health; in the Wei and Jin Dynasties incense had been used by the literati; in the Northern Song Dynasty "fragrance is among all lanes". Rich category of aromatic plants were used for incense, expelling worm, medical and health and many other fields, and were used by smoked burn, wear, smoke bath, and beverage service etc.. Incense culture had become popular at that time. [3]

Incense use by the Ming Dynasty palace and folk was prevalent, not only related with the continuation of traditional culture, but also with Zheng He's seven voyages to the western seas. The trips strengthened relationships between China and many countries and regions in Asia and Africa, also introduced a large number of spcies and incense making skills from Somalia, Kenya, Indonesia and other contries. The incoming spices were maily pepper, sandalwood,etc.. [4] In the book "Dream of Red Mansions" incense use was a microcosm of the life of Qing Dynasty nobles, the incense makeup, aromatherapy, incense accessories, incense ceremony, and incense industry is worth exploration. "Dream of Red Mansions" has rich description of the incense, the names of people and places have a fragrant aroma, such as Xiangling, Tan Yun, Sheyue, Heng Wu school, 
Daoxiang village, Hanxiangge, and Nuanxiangwu . Most main characters were related to incense. [5]

In the Qing Dynasty, Yunnan, Tibet, Sichuan, Shandong, Jiangsu, Zhejiang, Guangdong, Hunan and other places had temporary incense market, especially the West Lake in Hangzhou. West Lake incense market started from February fifteen to May fifth of lunar calendar, which was a busy time of the year. People gathered in the temples around the West Lake in Hangzhou for worship. Incense culture can be fully reflected by all the incense. The types of incense included sandalwood and joss stick, and daily trading volume was hundreds of pounds for sandalwood and around thousands for joss stick. A small amount of incense was burnt and the remaining was given to the monks. Monks also took this opportunity to sale the temple beads and other special items. Incense market of the West Lake shows the social life of the people of South of the Yangtze River in Qing Dynasty by the duration of the market, pilgrims source, praying, market and other aspects. [6]

In modern times, Chinese nation ill fated, incense cultural development had also been greatly depressed, and was limited in the altars and temples. Today a lot of people think incense is a religious culture and feudal superstition. It is exciting that through the 20th century the Chinese people gradually appreciate Chinese traditional incense culture.

\section{Analysis of the Necessity of Quanzhou Maritime Silk Road Cultural Tourism Development}

\section{The Need for Structural Adjustment of Quanzhou Tourism Industry}

Problems in the Tourism Industry in Quanzhou. Quanzhou city located in southeastern Fujian Province, a strait away from Taiwan, one of the first 24 famous historic cities of culture designated by the State Council. Quanzhou has sea and mountains, hilly territory and beautiful scenery. Since the reform and opening, Quanzhou's tourism industry has developed rapidly, and has made important contributions to the transformation and upgrading of the industrial structure. Statistics show that in 2014, Quanzhou City received a total of 44.2826 million tourists, an increase of 18.74\%; total tourism revenue of 52.865 billion RMB yuan, an increase of $18.28 \%$. Quanzhou tourism industry has made achievements, but problems exist in that the total tourism revenue accounted for low proportion of Gross Demstic Product (GDP), single source of tourists and other issues. From the perspective of Southern Fujian culture and creative industries, there are two major problems in the tourism industry in Quanzhou.

Visitors are mainly on one day tour and stay for short time. Sampling survey in 2005 showed that the proportion of one day tour is quite large, accounting for $48.39 \%$, two day tour for $25.56 \%$, and three day tour for $26.05 \%$. Until today, Quanzhou one day tourists are still the majority. In May 1st, 2012 long weekend, Fujian province received a total of 3.9892 million domestic and foreign tourists, in which overnight tourists are 901.5 thousand, and one day tour visitors are 3.0877 million, accounting for $77.4 \%$. Fuzhou, Zhangzhou, Quanzhou, Putian, Sanming City one day tour proportion was more than $80 \%$, higher than the provincial average.

Tourism revenue structure is not reasonable, and the tourism industry chain is not perfect. During the 2015 Spring Festival holiday in Fujian Province, the per capita expense of tourists was higher in Xiamen, Quanzhou, Fuzhou and Nanping, and was 1031 yuan, 837 yuan, 719.04 yuan, and 695 yuan, respectively. Over the same period the per capita expense of tourists in Fujian and China was 656.7 yuan and 554.9 yuan, respectively. Although expense of tourists per capita in Quanzhou ranked high in Fujian and China, expense was mainly on entrance tickets. Among six elements of tourism, proportion of expense on eating, lodging, traveling and sightseeing are higher than that of entertaining and shopping. Shopping as one of the six elements in tourism, should account for a large proportion. In many countries and regions in the world, tourism revenue from sale of goods accounted for $30 \%$ to $40 \%$ of the total income of tourism foreign exchange. In developed shopping areas such as Hong Kong, Singapore and other regions, tourism shopping accounted for more than 50\%. While in Quanzhou, shopping accounted for only 15\%. [7] This shows that Quanzhou tourism industry chain is imperfect and tourism revenue structure is not reasonable. 
Reason Analysis. Tourists stay for a short time in Quanzhou, mostly on one day tour; the tourism industry chain is imperfect, entertaining and shopping expense is low. These indicate there are serious problems on the tourism product design. The current tourism product in Quanzhou is mainly static sightseeing, low level and single structure. Participating and experiencing tourism product with Southern Fujian creative culture is deficient. The extensive development mode without innovation and cultural connotation indicates that Quanzhou tourism industry and Southern Fujian culture creative industry has little integration and interaction.

\section{The Need for the Development of Quanzhou Cultural and Creative Tourism}

Culture creative industry focuses on product uniqueness, creativity and artistry and has enormous brand expansion potential. Quanzhou has huge potential for culture creativity since it is the core area of Southern Fujian culture and has the United Nations' first "Exhibition Center of World Multiculturalism". However, its resources are not fully explored and it is not creative. Culture creativity is the key to improve the product competition since resource itself can't transform into culture product advantage. Only when the resources are combined with creativity can they transform from historical value and art value into commercial value.

It is a trend for the culture, creativity and tourism industry to integrate. Cultural industry is to provide the product and service of culture and amusement activities for the public, the tourism industry involves various fields of six elements: "traveling, sightseeing, lodging, eating, shopping and entertaining" and with tourists consumption related departments. Creative industry is a high-end industry with thought, idea, knowledge, information, and culture as the core value chain. [8] It has innovative, osmotic, high added value, strong radiation force and high-tech features; it will integrate tourism resources, innovate tourism product, rich tourism industry chain and reshape the tourism industry system. Compared with the traditional tourism, creative tourism focuses on "creative", mainly reflected in "planning" on the exploration and utilization of cultural tourism resources and cultural connotation, so as to speed up the tourism industry structure optimization and upgrade, enhance the attractiveness of the tourism products, expand the tourism market, contribute to the tourism industry from extensive to intensive development. [9]

China incense culture has a long history, and is known with tea culture and flower culture as the three major cultural phenomena. In the history, incense is undoubtedly among the most widely used by the ancestors in their secular and spiritual lives. The emperors and even common citizens love incense; and it was used everywhere from the most sacred place of worship to the secular toilet bathroom. Incense can be used as mosquito repellent, exorcise of evil spirits, dirty removement, health improvement, etc..

Research on cultural tourism is voluminous, and incense culture research has become more and more recently. However, the combined research of the incense culture and tourism is not found. The author believes that the incense culture and creative tourism can highly fit together. Incense culture can extend the chain of the tourism industry, expand its breadth and depth, and incense culture tourism can produce added value that is even higher than that of the tea culture tourism. Quanzhou has an unique incense cultural resources. Integration of Maritime Silk Road incense culture and tourism, is an inexhaustible resource for the development of cultural tourism in Quanzhou. 
Table 1 Integration of maritime silk road incense culture and six elements of tourism in Quanzhou

\begin{tabular}{|c|c|c|}
\hline $\begin{array}{l}\text { Six elements of } \\
\text { tourism }\end{array}$ & $\begin{array}{l}\text { Integration of incense } \\
\text { culture and six elements of } \\
\text { tourism }\end{array}$ & Existing and future development of the incense cultural tourism \\
\hline \multirow{3}{*}{ Eating } & Food & $\begin{array}{l}\text { Sweet orange cake, Honglai chicken feet, Yongchun white duck soup, } \\
\text { Quzhou ginger duck, spiced rolls etc.. Chinese and Western herbical food } \\
\text { can be developed }\end{array}$ \\
\hline & Tea & $\begin{array}{l}\text { Quanzhou Anxi Tieguanyin tea, Yongchun Foshou tea can be made with } \\
\text { spice flowers. }\end{array}$ \\
\hline & Wine & $\begin{array}{l}\text { Glutinous rice wine and sweet potato wine of regional characteristics } \\
\text { can be considered, imitation of the Han Dynasty "Pepper wine" and } \\
\text { "chrysanthemum wine, imitation of Song Dynasty with cardamom, } \\
\text { ferulic, frankincense and other spices to make coriander wine, jasmine } \\
\text { wine, nutmeg wine, etc.. }\end{array}$ \\
\hline Lodging & $\begin{array}{l}\text { Incense pavilion, } \\
\text { sandalwood incense home }\end{array}$ & $\begin{array}{l}\text { Quanzhou can build incense farmhouse, inn, near vanilla or Yongchun } \\
\text { similar to ancient building, and develop aromatic cultural theme hotel } \\
\text { and villa for health. }\end{array}$ \\
\hline Traveling & Fragrant car & $\begin{array}{l}\text { In the vanilla world and modern leisure farm fragrant vanilla can be used } \\
\text { to decorate traditional wooden handcart }\end{array}$ \\
\hline \multirow{5}{*}{ Sightseeing } & $\begin{array}{l}\text { Maritime Silk Road spice } \\
\text { trade route travel }\end{array}$ & $\begin{array}{l}\text { Development of Quanzhou and Southeast Asia, South Asia, West Asia, } \\
\text { east coast of Africa and Europe antique spice trade route tour. }\end{array}$ \\
\hline & Incense culture museum & $\begin{array}{l}\text { Set up incense culture museum in Yongchun Dapu - China incense } \\
\text { capital, or in Pu's former residence in Quanzhou }\end{array}$ \\
\hline & Incense pavilion & $\begin{array}{l}\text { Quanzhou Meng Ya, Quanzhou "Sandaoxing" incense Pavilion, } \\
\text { Quanzhou wisdom incense free experience class etc. }\end{array}$ \\
\hline & Spice medicine and health & $\begin{array}{l}\text { Carry out Aromatherapy, make spice medicine according to the } \\
\text { traditional Chinese prescription health diet }\end{array}$ \\
\hline & Religious tourism & $\begin{array}{l}\text { Yongchun bamboo incense--- Yongchun Pu's family incense: } \\
\text { sandalwood, fragrant orchid, etc. There are three types of incense based } \\
\text { on its form. Incense can be developed in accordance with the different } \\
\text { religious rituals of Buddhism, Taoism, and Islam. }\end{array}$ \\
\hline \multirow{4}{*}{ Entertaining } & Vanilla world & Nanan vanilla world, Yongchun Dapu Chinese incense capital \\
\hline & Modern leisure farms & Vanilla Manor can be developed \\
\hline & $\begin{array}{l}\text { Incense culture tourism } \\
\text { festival }\end{array}$ & $\begin{array}{l}\text { Currently there is Xiamen Buddhist supplies exhibition. Quanzhou can } \\
\text { also develop incense Cultural Festival related to the religion }\end{array}$ \\
\hline & Incense production DIY & Yongchun Dapu - Chinese incense capital: incense production DIY \\
\hline Shopping & & $\begin{array}{l}\text { Yongchun Dapu - China incense shopping; existing Yongchun bamboo } \\
\text { incense, yangpi San, sophiscated incense, car incense; Yongchun Pu's } \\
\text { family incense; Yongchun county Wu Li Jie Pu Qinglan perfumed } \\
\text { chamber. Develop incense culture near the Incense Culture Creative } \\
\text { Industry Park, the incense trade street, market }\end{array}$ \\
\hline
\end{tabular}

Source: Done by the author.

\section{The Need to Carry Forward the Culture of the Maritime Silk Road}

The party's the third Plenary Session of the 18th CPC Central Committee proposed to promote the Silk Road Economic Belt, Maritime Silk Road Construction (referred to as "The Belt and Road '), the formation of a new pattern of all-round opening. At present, the national Development and Reform Commission is organizing the preparation of "The Belt and Road" overall planning. Quanzhou as the starting point of the Maritime Silk Road, its origins can be traced back more than a thousand years ago. Chinese incense culture has a long history, after the An-Shi rebellion, the western spice trade from the Land Silk Road was blocked, and the Maritime Silk Road began to play an important role. For the Song and Yuan Dynasties in Quanzhou, "Sea Spice Road" can be understood as the opposite of "Maritime Silk Road". In the late Song and early Yuan Dynasty, spices had become one of Quanzhou and China's imports of commodities, in which Arabian traders had great contribution. Arabian Pu Shougeng monopolied Quanzhou spices overseas trade for nearly 30 years. Yongchun, Quanzhou Pushi incense industry is the integration of the Chinese incense culture and the Arabian incense technology.

Wang Kang, president of the Chinese Incense Association thinks, in the Song and Yuan dynasties, Citong port had fragrance everywhere and was called "fragrant port" based on following: first, in the 1960s and 1970s unearthed ancient boat of Song Dynasty from Quanzhou Houzhu port, in addition to the porcelain and silk, the majority of goods was the spice, and weighs 2000 pounds, the 
incense and other rare spice accounted for a large percentage, indicating that the spices had been the major trade commodities; second, Dapu Town, Yongchun County, Quanzhou incense industry has lasted more than a thousand years, Yongchun County river Taoxi became a fragrant river because of transporting incense; third, Yongchun County has history of planting fragrant trees. Many villages and towns in Yongchun County have superior ecological conditions, "large area is suitable for planting orange and tea, incense trees." Wang Kang believes that Quanzhou, as China's first East Asian culture capatical, with the historical opportunity of 'Maritime Silk Road', trading industry of Citong port, and a unique ecological advantages, it is possible to build Quanzhou Yongchun as domestic famous fragrant city.

To Quanzhou, Maritime Silk Road, Maritme Spice Road is not only a major maritime trade channel, but also a rich connotation of the cultural carrier. Therefore, Quanzhou incense culture tourism can not only expand the connotation of cultural and creative tourism, but also contribute to development of Maritime Silk Road culture.

\section{Conclusions}

Maritime Silk Road incense culture can integrate with six elements of tourism. As mentioned above, the entrance ticket is the main expense of Quanzhou domestic and foreign tourists. Among the six elements, traveling, sightseeing, lodging, eating, accounted a larger proportion, shopping and entertaining accounted for a smaller proportion. Tourism industry chain is not perfect, tourism income structure is unreasonable. The development of cultural creative tourism, Maritime Silk Road cultural creative tourism can be used as a good example. The integration of the six elements of tourism and the incense culture can broaden the tourism industry chain, and extend the staying time of tourists in Quanzhou(See Table 1).

\section{Acknowledgement}

This research was financially supported by Quanzhou Normal University 3rd academic leader training and Undergraduate teaching reform project of Quanzhou Normal University (JAX14050), and by the Chinese Academy of Social Sciences Research Center of Minnan culture research base (Quanzhou).

\section{References}

[1] Fu Jingliang. China Incense Culture [M]. Ji'nan: Qilu press, 2008, preface, 3.

[2] Xiao Jun. The Origin of Chinese Incense Culture [J]. Journal of Yangtze University (SOCIAL SCIENCE EDITION), 2011, (9): 168-169.

[3] Fu Jingliang. China Incense Culture [M]. Ji'nan: Qilu press, 2008, preface, 3-5.

[4] Yan Xiao Qing. Zheng He, Ming Dynasty and the Western Regions Tributary Trade with China [J]. Research on Chinese Economic History, 2012, (2): 180-185.

[5] Yan Xiaoqing, Zhang Tao. Incense Story of "Dream of Red Mansions". Study on the Ming and Qing Novels [J]., 2008, (3): 139-149.

[6] Cai Yulong. A brief discussion on the incense market in the southern cities in the Qing Dynasty based on the West Lake of Hangzhou, China. Histroy Curriculum 2010, (20): 24-29.

[7] Yecheng Feng. The historical and cultural city tourism commodity development strategy research on the west side of the Straits -- Taking Quanzhou tourism commodity market as an example [J]. science and technology and industry, 2011, (12):23-26.

[8] Wang Zhaofeng, Yang Qin. Research on the development of ethnic cultural tourism creative industry based on the theory of property rights [J]. Guizhou national research, 2010, (5): 99-104. 
[9] Chen Shulan, Liu Liping, Fu Jingbao. Optimization and upgrading of the tourism industry structure in Henan Province from cultural and creative perspective [J]. Economic geography, 2011, (8): 1392-1396. 